\title{
Rate and associated factors of non-retention of mother-baby pairs in HIV care in the elimination of mother-to-child transmission programme, Gulu-Uganda: a cohort study
}

Gerald Obai ${ }^{1 *}$, Ruth Mubeezi ${ }^{2}$ and Fredrick Makumbi ${ }^{3}$

\begin{abstract}
Background: Poor retention in HIV care of mother-baby pairs remains a public health challenge in the elimination of mother-to-child transmission (eMTCT) of HIV. We determined the rate of non-retention and time to non-retention of mother-baby pairs and associated factors in Gulu district, Northern Uganda.
\end{abstract}

Methods: Mother-baby pairs enrolled into the eMTCT programme at Gulu Regional Referral Hospital (GRRH) and Lacor Hospital (LH) were retrospectively followed for 18 months. The primary outcomes were the rate of non-retention and time to non-retention of mother-baby pairs in HIV care. Data were abstracted from the antiretroviral treatment and early infant diagnosis (EID) registers, and mother/baby appointment books at the health facilities. Additional data on possible reasons for non-retention were obtained from cross-sectional interviews of mothers. Time to non-retention was calculated as the duration between enrolment of mother-baby pair into care and the date when the mother and/or baby missed a scheduled visit and did not return within 30 days. Factors associated with time to non-retention were assessed using Cox proportional hazards regression analysis. The measures of association were expressed as hazards ratio (HR) with $95 \%$ confidence intervals. Alpha was set at 0.05 . The adjusted analysis includes variables with $p<0.2$ in the bivariable analysis or considered potential confounders. The Analysis used Stata version 12.

Results: A total of 410 mother-baby pairs were enrolled in this study. Overall, non-retention by 18 month was 30.5\%; higher at GRRH (34.7\%) than LH (25.8\%), $p=0.049$. Non-retention was higher among pairs where the infant had no EID, adjusted (adj) HR=5.81; $95 \% \mathrm{Cl}(2.55,13.24)$, non-disclosure of mother's HIV status, adj.HR=1.86; $95 \% \mathrm{Cl}(1.22,2.85)$, and lack of privacy during counselling session, adj. $\mathrm{HR}=1.86 ; 95 \% \mathrm{Cl}(1.26,2.85)$. Non-retention was about $60 \%$ lower [adj. $\mathrm{HR}=0.43 ; 95 \% \mathrm{Cl}(0.20,0.92)$ ] among pairs where the mothers understood and appreciated the importance of adhering to all clinic appointments together with the baby.

Conclusion: Nearly a third of mother-baby pairs are not retained in HIV care. Lack of EID services, poor quality service, non-disclosure of mother's HIV status, and understanding the importance of adhering to all appointments together with the baby, were associated with time to non-retention.

Keywords: Mother-baby pairs, Non-retention, eMTCT, Gulu, Hoima, Hospitals, Uganda

\footnotetext{
*Correspondence: lekobai@gmail.com

'Department of Physiology, Faculty of Medicine, Gulu University, P.O. Box

166, Gulu, Uganda

Full list of author information is available at the end of the article
} International License (http://creativecommons.org/licenses/by/4.0/), which permits unrestricted use, distribution, and reproduction in any medium, provided you give appropriate credit to the original author(s) and the source, provide a link to the Creative Commons license, and indicate if changes were made. The Creative Commons Public Domain Dedication waiver (http://creativecommons.org/publicdomain/zero/1.0/) applies to the data made available in this article, unless otherwise stated. 


\section{Background}

Mother-to-child transmission (MTCT) of HIV remains the most common source of paediatric HIV infection, accounting for $95 \%$ of cases, of whom, $90 \%$ are in subSaharan Africa [1]. In the absence of any interventions, the risk of mother-to-child transmission may be up to $25 \%$ during pregnancy, labour, and delivery. There is an additional risk of $5-20 \%$ during the breastfeeding period, leading to an overall transmission rate of up to $45 \%$ [2]. In Uganda, there has been an increase in the prevalence of HIV from $6.4 \%$ in 2009 to $7.3 \%$ in 2011, with women being disproportionately affected $(8.3 \%)$ as compared to men $(6.1 \%)$ [3]. The situation is worse in Gulu where the prevalence is $10.3 \%$ [4]. As a result of the high prevalence of HIV among women, up to $6.5 \%$ of pregnant women in Uganda are HIV-infected [4]. In 2009 in Uganda, an estimated 149,661 children below the age of 15 years were living with HIV, of whom about $90 \%$ acquired the infection through MTCT [5].

In 2012, the Ugandan government embraced the call by the World Health Organisation to eliminate motherto-child transmission (eMTCT) of HIV by 2015. To achieve the target of eMTCT, programmes were to followup and treat HIV-positive mothers together with their children until the $18^{\text {th }}$ month of the child's life when the final HIV status of the infant is determined [6, 7]. However, in sub-Saharan Africa, up to $81 \%$ of mother-baby pairs are not retained in care six months after delivery $[8,9]$. In Uganda, loss to follow-up (LTFU) of motherbaby pair has been reported to be 53.4\% [10]. Literature shows that the majority of mother-baby pairs who are not retained in eMTCT programmes are due to LTFU and not death [11], suggesting that the infants remain alive, but at higher risk of acquisition of HIV from their mother than infants who remain in care. Non-retention, therefore, hinders programmes from maximally achieving the goals of eMTCT [12]. Non-retention of HIV-exposed infants also denies the infants who are infected, the opportunity for prompt diagnosis and treatment; yet paediatric HIV-associated morbidity and mortality can be prevented with early diagnosis and treatment [12].

While the risk of HIV transmission through breastfeeding continues for up to two years, few exposed infants are re-tested after testing at 4-6 weeks of life $[13,14]$, which only identifies those children infected in the uterus or during delivery [15]. Consequently, many HIV-exposed children remain with unknown HIV status.

This study set out to determine, the rate of nonretained pairs, the time to non-retention, and factors associated with time to non-retention, in the 18 months after birth for mother-baby pairs in eMTCT in HIV care programmes in Gulu district, Northern Uganda. The findings of this study will help to develop strategies aimed at improving retention of mother-baby pairs in care which may reduce the risk of MTCT of HIV during the postpartum period.

\section{Methods \\ Study design, setting and population}

This was a retrospective single cohort of HIV-positive mothers and their HIV-exposed babies born between January 2010 and December 2012 at either Lacor Hospital (LH) or Gulu Regional Referral Hospital (GRRH), both located in Gulu district, Northern Uganda. We also collected additional data on possible reasons for nonretention, in a cross-sectional manner. We identified some of the mothers at the hospital, while others were traced using telephone contacts or sketch maps in their hospital care cards, for face-to-face interviews. The study was conducted between June and August 2014. The entire cohort had at least 18 months of being at risk of experiencing non-retention by June 2014.

Lacor hospital and GRRH are the two largest hospitals in Acholi sub-region, serving patients from the entire sub-region and beyond. Gulu district is located at, 02 45 N, 32 00E, approximately 340 kilometres North of Uganda's capital city, Kampala. The population of Gulu district is 443,733 [16].

Only mothers aged 15 years and above and who were permanent residents of the study area were eligible to take part in the study. Mothers aged 15-17 years are emancipated minors who were included in their own rights, as provided for in the Research Ethics Committee (REC) guidelines [17]. Mothers who had delivered from other hospitals but enrolled in either GRRH or LH and those who had transferred care to other facilities were excluded from the study so as to minimise data incompleteness but to also maintain study eligibility.

\section{Sample size and sampling procedure}

This study had two outcome variables, i) rate and ii) time to non-retention. We used the online StatsToDo software [18] to determine the sample size for the time to-non-retention, with 5\% type-I error and power of $80 \%$, giving a sample size of 393 mother-baby pairs. For the second outcome variable, rate non-retained within 18 months, a Kish Leslie [19] formula was used assuming a $53.4 \%$ rate of non-retention in Northern Uganda from a previous study [10], 5\% margin of error. A $10 \%$ nonresponse rate was factored into the calculations. The largest sample size was considered for both outcomes because the study population was the same [20]. We sampled the study participants from the hospital ART registers. A total of 476 mother-baby pairs were eligible for the study (Fig. 1). Half of the study participants were recruited from each of the hospitals, and simple random sampling was conducted to enrol the study participants. The patient hospital number from the register was written 


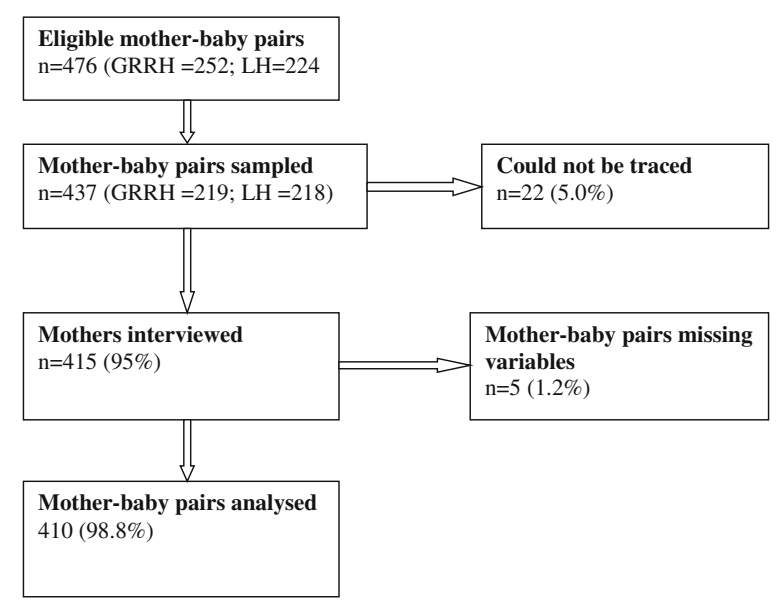

Fig. 1 Diagram of mother-baby pairs recruitment into the study. A total of 476 mother-baby pairs were eligible for this study. We sampled 437 mother-baby pairs but 22 could not be traced for the face-to-face interviews. We therefore, collected data from 415 mother-baby pairs. However, we excluded five mother-baby pairs from the final analysis because they lacked or had unclear important variables like appointment dates missed, which were very important in determining non-retention in HIV care.

on a piece of paper. The pieces of paper were put in a basin. We then randomly picked one at a time until the required sample size was attained. Probability sampling was used to avoid selection bias.

\section{Definition of variables}

The variables for this study were derived from Andersen's model of health care utilisation [21]. The outcome variables of this study were non-retention at 18 months, and time to non-retention of mother-baby pair in HIV care. Non-retention was defined as a mother and/or baby not returning at the facility within a period of 30 days after missing a scheduled visit. The rate of non-retention was calculated as the number of mother-baby pairs not retained in HIV care over the 18 month period divided by the total number of mother-baby pairs enrolled in the study. This was categorised as (" 0 " = retained and "1" = non-retained).

Time to non-retention was calculated as the duration from mother-baby pair enrolment into HIV care and when the mother and/or baby missed a scheduled visit and did not return for care within a period of 30 days. The unit of measurement was months. The period considered was from delivery to 18 months, thus entry into this study was from the date of birth. The event of interest was non-retention. Once the event of interest occurred, no re-entry in the study was allowed for this analysis.

Infant data collected included sex (male/female), feeding method (exclusive breastfeeding/mixed feeding); EID at
4-6 weeks (done/not done), and EID result (positive/ negative). Maternal data collected included; age, categorised as 15-19, 20-29, $\geq 30$ to reflect the health seeking behaviours among pregnant women in those categories, which also affect healthcare utilisation; marital status (categorised as never married, married, previously married), education (categorised on the basis of education levels in Uganda -none, primary, secondary, tertiary), religion (categorised on the basis of the main religious denominations in Uganda - Protestant, Catholic, Muslim, Pentecostal, plus the category Others, which incorporated religion or beliefs such as atheism, Hinduism, and Seventh Day Adventism, which are less widely practiced in Uganda). Occupation (categorised as housewife, farmer, wage/salaried workers, manual labour, others). This categorisation was on the basis of the widely recognised income earning sources of women in Uganda. Transport was categorised on the basis of the means of transport commonly used in Uganda (walk/bicycle/ motorcycle/vehicle). Other maternal demographic data collected were residence (urban/rural), distance to the health facility (recoded as $0-5 \mathrm{~km}, 6-10 \mathrm{~km},>10 \mathrm{~km}$ ). Wealth index as determined by monthly income was categorised as [lowest $=<\mathrm{UGX} .50,000(\sim \$ 15)$, second lowest $=$ UGX. 50,000 $-\leq 100,000(\$ 15.1-\$ 30)$, middle $=$ UGX. 100,000 - <300,000 (\$30.1 - \$90), second highest = UGX. 300,000 - <500,000 (\$90.1 - \$151.5), highest = UGX. $\geq 500,000(\geq \$ 151.5)]$. The cut-off points for categorisation of wealth index were refined after pre-testing the study tools. Other data collected were the number of times delivered while HIV positive $(1,2+)$, partner disclosure (yes/ no), spouse testing for HIV (yes/no), and the mother's opinion about keeping all the hospital appointments (not important/important).

The quality of health care variables included privacy during counselling session (categorised as (yes/no), and waiting time, which was categorised as not considered long by the respondent versus considered long.

\section{Data collection}

We abstracted data on HIV diagnosis, eMTCT enrolment, infant feeding, mother's age, residence, marital status, distance to health facility, delivery, and follow-up outcomes from ART/EID registers, mother/baby appointment books kept at the health facilities, and exposed infant clinical charts. Records from the ART and EID registers and appointment books were used to determine the rate of non-retention of mother-baby pairs in care during the first 18 months of infant life. A structured questionnaire was developed to collect additional data on possible reasons for non-retention of motherbaby pair sampled from the clinic records. These were data not captured in the medical records but are considered important in understanding non-retention. 
The additional data included; the highest level of education attained, religion, occupation, means of transport to the hospital, wealth index, number of previous deliveries while HIV positive, whether the spouse had tested for HIV or not, and the mother's opinion on the need to keep all appointments together with the baby, and the quality of care as determined by privacy and waiting time at the health facility. Some of the mothers were interviewed at the hospitals during their routine visits for care, while others were traced and interviewed from a place of their choice. The questionnaire and data abstraction form were pretested in a health facility setting. They were then refined to improve their validity and reliability. Trained research assistants with experience of working in HIV/AIDS units in hospitals collected data.

\section{Data management and analysis}

Data were checked for completeness and accuracy at the end of each day of data collection. Double entry of data in an Excel spreadsheet was performed to detect inconsistent and missing entries. Data were then cleaned to eliminate errors in data entry and backed up regularly. We then exported data to Stata version 12 for statistical analysis.

We did survival analysis because it took into account the time to event (non-retention) information which is very important considering the long term and cascade nature of care in eMTCT of HIV. Data with missing outcome variables were excluded from the analysis. The missing data did not have any effect on our analysis since we had factored in a $10 \%$ non-response in the sample size calculations. In univariable analysis, summary statistics for categorical variables were analysed and presented as, proportions, frequencies, and graphs. Continuous variables are presented as range, mean, standard deviation (SD), and median. Kaplan-Meier methods were used to estimate the probabilities of non-retention of mother-baby pairs in the eMTCT programme by 18 months postpartum. In the bivariable analyses, the Log-Rank test was used to determine if there were any significant differences in the survival experiences between any two categories. Each categorical variable was assessed independently to test for association between the outcome variable (time to non-retention) and the independent variable. Cox proportional hazards regression analysis was used to determine independent association between mother-baby characteristics and time to non-retention, with variables that had $p<0.20$ at bivariable analyses or considered potential confounders being included in the multivariable analyses. We used hazards ratio as a measure of association.

\section{Results}

Mother-baby pair characteristics and main findings

A total of 410 mother-baby pairs took part in this study, providing a $95 \%$ response rate. Just over a half (52.7\%) were from GRRH. The mothers were aged 15-44 years with a mean (SD) age of 28.6 (5.9) years. The majority of eligible participants were aged 20-29 years (53\%), married (84.6\%), and had attained some level of education (primary $38.1 \%$ or secondary $33.9 \%$ ). Exclusive breastfeeding during the first six months was common (54.2\%). EID was absent in 11 infants (2.7\%), whilst 23 infants $(5.8 \%)$ were detected as HIV positive by six weeks. Up to $83.2 \%$ of mothers disclosed their HIVstatus (Table 1).

Nearly a third (30.5\%) of the mother-baby pairs were not retained in care by end of month 18; higher in GRRH (34.7\%) than in LH (25.8\%), $p=0.049$. The probability of non-retention was 0.12 at six months, 0.19 at twelve months and 0.3 at 18 months. The 18 month follow-up period was not long enough for the overall median time to non-retention to be ascertained (Fig. 2). It was calculated to be two months for babies with no EID, 15 months for mothers not disclosing their serostatus, while that for mothers who reported lack of privacy during counselling session it was 16 months (Fig. 3). The median time for those with EID, who disclosed their HIV serostatus, and those who reported that there was privacy during counselling could not be ascertained during the 18 month follow-up time.

Early infant diagnosis, education level attained, religion, occupation, transport, disclosure of HIV serostatus, the number of times delivered while HIV positive, spouse testing for HIV, quality of counselling, and waiting time were all significant factors for time to non-retention at the bivariable level (Table 2). Factors independently associated with time to non-retention were; absence of EID, adj. $\mathrm{HR}=5.8$; CI $(2.55,13.24)$, disclosing HIV status to a sexual partner adj. HR 1.86; CI (1.22, 2.85), and quality of counselling session adj. HR 1.86; CI $(1.26,2.85)$. Knowledge of the importance of adherence to all appointments together with the baby was associated with lower risk of non-retention adj. HR 0.43; CI $(0.20,0.92)$ (Table 3$)$.

\section{Discussion}

Nearly one-third of mother-baby pairs in this cohort were not retained in HIV care, which is less than previously reported in Northern Uganda [10]. However, if virtual elimination of mother-to-child transmission of HIV is to be achieved, then all the mother-baby pairs should be retained in HIV care. Studies have shown that nonretention affects continuous follow-up of HIV-exposed infants which allows early identification of infected infants and prompt initiation of treatment [22]. Non-retention also compromises the use of ART by the mother and baby 
Table 1 Mother/baby characteristics

\begin{tabular}{|c|c|c|}
\hline Parameter & Number & Percent \\
\hline \multicolumn{3}{|l|}{ Baby's sex } \\
\hline Male & 204 & 49.8 \\
\hline Female & 206 & 50.2 \\
\hline \multicolumn{3}{|l|}{ Feeding method } \\
\hline Exclusive breastfeeding & 222 & 54.2 \\
\hline Mixed feeding & 188 & 45.8 \\
\hline \multicolumn{3}{|l|}{ Early Infant Diagnosis (EID) } \\
\hline Done & 399 & 97.3 \\
\hline Not done & 11 & 2.7 \\
\hline \multicolumn{3}{|l|}{ EID result } \\
\hline Positive & 23 & 5.8 \\
\hline Negative & 376 & 94.2 \\
\hline \multicolumn{3}{|l|}{ Mother's age } \\
\hline $15-19$ & 20 & 4.9 \\
\hline $20-29$ & 220 & 53.7 \\
\hline$\geq 30$ & 170 & 41.4 \\
\hline \multicolumn{3}{|l|}{ Marital status } \\
\hline Never married & 23 & 5.6 \\
\hline Married & 347 & 84.6 \\
\hline Previously married & 40 & 9.8 \\
\hline \multicolumn{3}{|l|}{ Education } \\
\hline None & 70 & 17.1 \\
\hline Primary & 156 & 38.1 \\
\hline Secondary & 139 & 33.9 \\
\hline Tertiary & 45 & 10.9 \\
\hline \multicolumn{3}{|l|}{ Religion } \\
\hline Protestant & 105 & 25.6 \\
\hline Catholic & 227 & 55.4 \\
\hline Muslim & 28 & 6.8 \\
\hline Pentecostal & 36 & 8.8 \\
\hline Others & 14 & 3.4 \\
\hline \multicolumn{3}{|l|}{ Occupation } \\
\hline Housewife & 125 & 30.5 \\
\hline Farmer & 149 & 36.3 \\
\hline Wage/salaried workers & 71 & 17.3 \\
\hline Manual labour & 14 & 3.4 \\
\hline Others & 51 & 12.5 \\
\hline \multicolumn{3}{|l|}{ Transport } \\
\hline Walk & 91 & 22.2 \\
\hline Bicycle & 61 & 14.9 \\
\hline Motorcycle & 167 & 40.7 \\
\hline Vehicle & 91 & 22.2 \\
\hline \multicolumn{3}{|l|}{ Wealth index } \\
\hline Lowest & 125 & 30.5 \\
\hline
\end{tabular}

Table 1 Mother/baby characteristics (Continued)

\begin{tabular}{|c|c|c|}
\hline Second lowest & 128 & 31.2 \\
\hline Middle & 104 & 25.4 \\
\hline Second highest & 37 & 9.0 \\
\hline Highest & 16 & 3.9 \\
\hline \multicolumn{3}{|l|}{ Residence } \\
\hline Urban & 259 & 63.2 \\
\hline Rural & 151 & 36.8 \\
\hline \multicolumn{3}{|c|}{ Distance to health facility } \\
\hline $0-5 \mathrm{~km}$ & 223 & 54.4 \\
\hline $6-10$ km & 94 & 22.9 \\
\hline$>10 \mathrm{~km}$ & 93 & 22.7 \\
\hline \multicolumn{3}{|c|}{ No. Of times delivered while HIV+ } \\
\hline 1 & 214 & 52.2 \\
\hline $2+$ & 196 & 47.8 \\
\hline \multicolumn{3}{|l|}{ Partner disclosure } \\
\hline Yes & 341 & 83.2 \\
\hline No & 69 & 16.8 \\
\hline \multicolumn{3}{|l|}{ Spouse tested } \\
\hline Yes & 316 & 77.1 \\
\hline No & 94 & 22.9 \\
\hline \multicolumn{3}{|c|}{ Keeping all appointments with baby } \\
\hline Not important & 31 & 7.6 \\
\hline Important & 379 & 92.4 \\
\hline \multicolumn{3}{|c|}{ Quality of counselling (privacy) } \\
\hline Yes & 316 & 77.1 \\
\hline No & 94 & 22.9 \\
\hline \multicolumn{3}{|l|}{ Waiting time } \\
\hline Not long & 177 & 43.2 \\
\hline Long & 233 & 56.8 \\
\hline
\end{tabular}

which is important to prevent transmission of HIV during the breastfeeding period. The consequence for this is increased risk of MTCT of HIV.

Health facility factors such as; unavailable EID at 4-6 weeks, and poor quality counselling services as determined by lack of privacy during counselling session, and personal factors, such as; non-disclosure of mother's HIV serostatus to the partner, and the mother's knowledge of the importance of adherence to all appointments together with the baby were associated with time to non-retention in HIV care. Time to non-retention was shorter among mothers with babies who did not undergo EID at 4 to 6 weeks compared to those motherbaby pairs who had EID at 4 to 6 weeks postpartum, as recommended by WHO [23]. Failure to carry out EID could be due to shortages and interrupted supplies of materials, which have been reported to be contributing factors for non-retention [24]. When mothers do not 


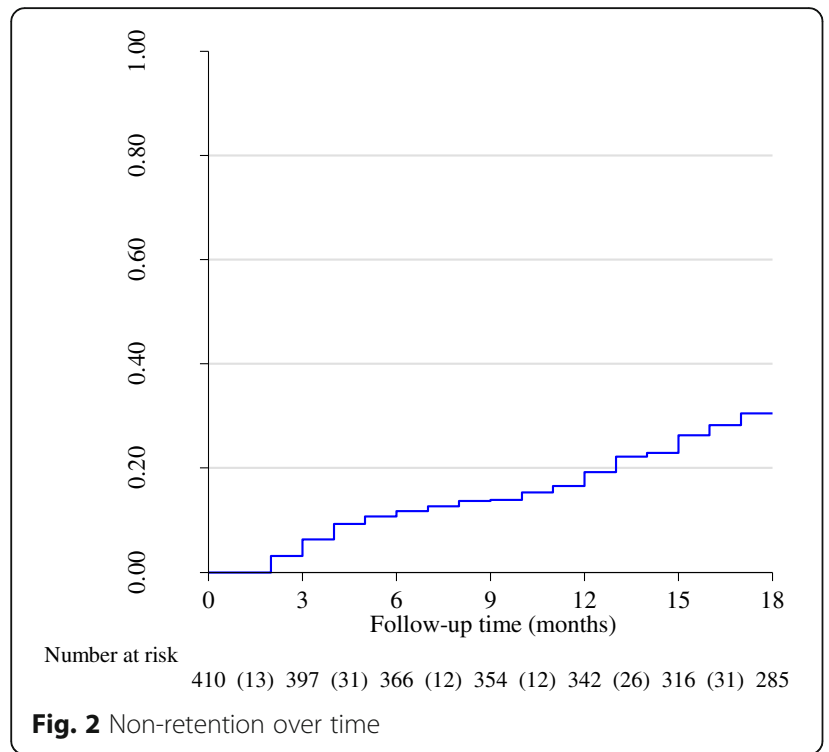

receive services during follow-up visits, some studies have shown that they lose interest in the programme as they may feel that the health workers do not care about them [25]. This should be avoided as EID allows for early initiation of ART to improve survival in infants who are HIV-infected [26, 27]. Starting treatment early is important because when children are already severely immune-compromised, they fail to regain full immune function even after several years of treatment [28]. As a result, children who are initiated on ART late are more likely to die compared to when treatment is started early. Therefore, health departments should ensure constant availability of test kits for EID.

Mothers who felt that there was no privacy during counselling were at increased risk of non-retention. Their median duration in HIV care was 16 months. This finding is similar to that reported in Kenya [29]. Two possible explanations for lack of privacy are inadequate

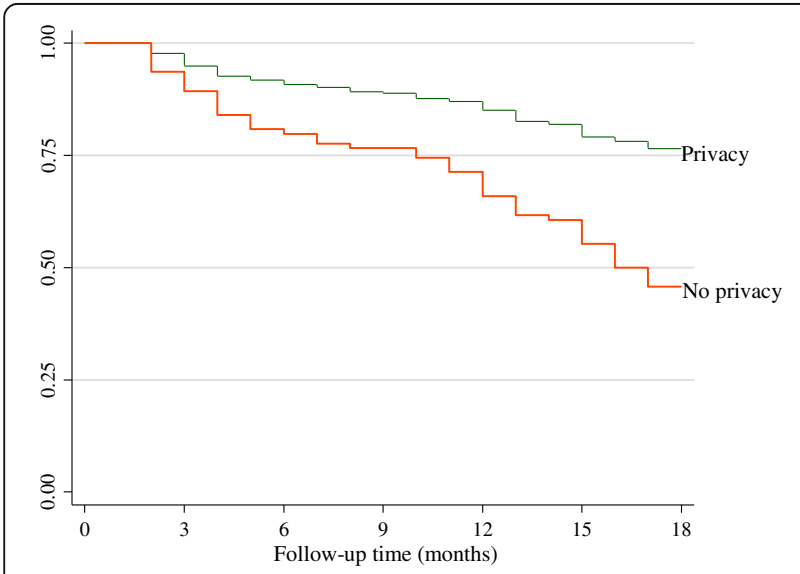

Fig. 3 Plot of Kaplan-Meir for privacy
Table 2 Result of Log-Rank test of mother-baby non-retention in HIV care

\begin{tabular}{lll}
\hline Parameter & Not-retained/total & \multicolumn{2}{l}{ Percent not-retained } \\
\cline { 3 - 3 } & $n$ & P-value
\end{tabular}

Baby's sex

$\begin{array}{llll}\text { Male } & 60 / 204 & 29.4 & \\ \text { Female } & 65 / 206 & 32.0 & 0.56\end{array}$

Feeding method

Mixed feeding

$62 / 188$

28.4

$33 \quad 0.48$

Early Infant diagnosis (EID)

Done

$115 / 399 \quad 28.8$

Not done

$10 / 11$

90.9

$<0.001$

EID result

Positive

$9 / 23$

39.1

Negative

$106 / 376$

28.1

0.24

Mother's age

$15-19$

$4 / 20$

20.0

20-29

$74 / 220$

33.6

$\geq 30$

$47 / 170$

28.2

Marital status

Never married

$8 / 23$

34.8

Married

$101 / 347$

29.1

0.44

Previously married

$16 / 40$

40.0

Education

None

$36 / 70$

51.4

Primary

44/156

28.2

Secondary

$37 / 139$

26.6

Tertiary

$8 / 45$

17.8

Religion

$\begin{array}{lll}\text { Protestant } & 40 / 105 & 39.1\end{array}$

Catholic

$61 / 227$

Muslim

Pentecostal

$12 / 28$

0.04

Others

$11 / 36$

42.9

30.6

$1 / 14$

7.1

Occupation

Housewife

$54 / 125$

43.2

Farmer

$36 / 149$

24.2

Wage/salaried workers

17/71

23.9

0.01

Manual labour

$4 / 14$

28.6

Others

$14 / 51$

27.5

Wealth index

$\begin{array}{lll}\text { Lowest } & 45 / 125 & 36.0 \\ \text { Second lowest } & 43 / 128 & 33.2 \\ \text { Middle } & 24 / 104 & 23.1 \\ \text { Second highest } & 10 / 37 & 27.0 \\ \text { Highest } & 3 / 16 & 18.8\end{array}$


Table 2 Result of Log-Rank test of mother-baby non-retention in HIV care (Continued)

\begin{tabular}{|c|c|c|c|}
\hline \multicolumn{4}{|l|}{ Residence } \\
\hline Urban & $84 / 259$ & 32.4 & \\
\hline Rural & $41 / 151$ & 27.2 & 0.26 \\
\hline \multicolumn{4}{|c|}{ Distance from health facility } \\
\hline $0-5 \mathrm{~km}$ & $72 / 223$ & 32.3 & \\
\hline $6-10 \mathrm{~km}$ & $25 / 94$ & 26.6 & 0.60 \\
\hline$>10 \mathrm{~km}$ & $28 / 93$ & 30.1 & \\
\hline \multicolumn{4}{|l|}{ Transport } \\
\hline Walk & $42 / 91$ & 46.2 & \\
\hline Bicycle & $20 / 61$ & 32.8 & \\
\hline Motorcycle & $46 / 167$ & 27.5 & 0.001 \\
\hline Vehicle & $17 / 91$ & 18.7 & \\
\hline \multicolumn{4}{|c|}{ No. of times delivered while HIV+ } \\
\hline 1 & $76 / 214$ & 35.5 & \\
\hline $2+$ & $49 / 196$ & 25.0 & 0.02 \\
\hline \multicolumn{4}{|l|}{ Partner disclosure } \\
\hline Yes & $86 / 341$ & 25.2 & \\
\hline No & $39 / 69$ & 56.5 & $<0.001$ \\
\hline \multicolumn{4}{|l|}{ Spouse tested } \\
\hline Yes & $80 / 316$ & 25.3 & \\
\hline No & $45 / 94$ & 47.9 & $<0.001$ \\
\hline \multicolumn{4}{|c|}{ Keeping all appointment with baby } \\
\hline Not important & $17 / 31$ & 54.8 & \\
\hline Important & $108 / 379$ & 28.5 & 0.002 \\
\hline \multicolumn{4}{|c|}{ Quality of counselling (privacy) } \\
\hline Yes & $74 / 316$ & 23.4 & \\
\hline No & $51 / 94$ & 54.3 & $<0.001$ \\
\hline \multicolumn{4}{|l|}{ Waiting time } \\
\hline Not long & $40 / 177$ & 22.6 & \\
\hline Long & $85 / 233$ & 36.5 & 0.002 \\
\hline
\end{tabular}

space or poor organisation of services within health facility, which compromises privacy and thus the confidentiality of mothers during counselling sessions [24]. Because of the stigma associated with HIV infection, and fear of involuntary disclosure of HIV status [25, 30], a mother who feels that her privacy is not being guaranteed may decide to opt out of long-term HIV care, which consequently increases the risk of maternal transmission of HIV through breastfeeding. Counselling rooms should ensure privacy so as to enable mothers to concentrate on the message being passed to them. This positive effect is emphasised in this study, which revealed approximately $60 \%$ lower risk of non-retention among pairs where the mothers understood and appreciated the importance of adhering to all clinic appointments together with their babies.
Table 3 Unadjusted and adjusted HR for non-retention in HIV care by mother-baby characteristics

\begin{tabular}{|c|c|c|c|}
\hline Parameter & $\begin{array}{l}\text { Unadjusted } \\
\text { HR (95\% Cl) }\end{array}$ & $\begin{array}{l}\text { Adjusted HR } \\
(95 \% \mathrm{Cl})\end{array}$ & $P$-value \\
\hline \multicolumn{4}{|l|}{ Baby's sex } \\
\hline Male & 1.0 & & \\
\hline Female & $1.07(0.75,1.51)$ & & \\
\hline \multicolumn{4}{|l|}{ Feeding method } \\
\hline EBF & 1.0 & & \\
\hline Mixed feeding & $1.13(0.80,1.61)$ & & \\
\hline \multicolumn{4}{|l|}{ Early Infant Diagnosis (EID) } \\
\hline Done & 1.0 & 1.0 & \\
\hline Not done & $13.19(6.75,25.77)$ & $5.81(2.55,13.24)$ & $<0.001$ \\
\hline \multicolumn{4}{|l|}{ EID result } \\
\hline Positive & 1.0 & & \\
\hline Negative & $0.66(0.33,1.31)$ & & \\
\hline \multicolumn{4}{|l|}{ Mother's age } \\
\hline $15-20$ & 1.0 & & \\
\hline $20-29$ & $1.83(0.66,5.00)$ & & \\
\hline$\geq 30$ & $1.51(0.55,4.20)$ & & \\
\hline \multicolumn{4}{|l|}{ Marital status } \\
\hline Never married & 1.0 & & \\
\hline Married & $0.81(0.40,1.67)$ & & \\
\hline Previously married & $1.12(0.48,2.61)$ & & \\
\hline \multicolumn{4}{|l|}{ Education } \\
\hline None & 1.0 & & \\
\hline Primary & $0.49(0.32,0.77)$ & & \\
\hline Secondary & $0.48(0.31,0.76)$ & & \\
\hline Tertiary & $0.30(0.14,0.63)$ & & \\
\hline \multicolumn{4}{|l|}{ Occupation } \\
\hline Housewife & 1.0 & & \\
\hline Farmer & $0.51(0.34,0.78)$ & & \\
\hline Wage/salaried worker & $0.50(0.29,0.86)$ & & \\
\hline Manual labour & $0.60(0.22,1.65)$ & & \\
\hline Others & $0.57(0.32,1.03)$ & & \\
\hline \multicolumn{4}{|l|}{ Religion } \\
\hline Protestant & 1.0 & & \\
\hline Catholic & $0.61(0.41,0.91)$ & & \\
\hline Muslim & $1.13(0.60,2.15)$ & & \\
\hline Pentecostal & $0.77(0.40,1.50)$ & & \\
\hline Others & $0.15(0.02,1.08)$ & & \\
\hline \multicolumn{4}{|l|}{ Transport } \\
\hline Walk & 1.0 & & \\
\hline Bicycle & $0.77(0.45,1.30)$ & & \\
\hline Motorcycle & $0.56(0.37,0.86)$ & & \\
\hline Vehicle & $0.36(0.21,0.65)$ & & \\
\hline
\end{tabular}


Table 3 Unadjusted and adjusted HR for non-retention in HIV care by mother-baby characteristics (Continued)

\begin{tabular}{|c|c|c|c|}
\hline \multicolumn{4}{|c|}{ Distance to health facility } \\
\hline $0-5 \mathrm{~km}$ & \multicolumn{3}{|l|}{1.0} \\
\hline $6-10 \mathrm{~km}$ & \multicolumn{3}{|l|}{$0.80(0.50,1.27)$} \\
\hline$>10 \mathrm{~km}$ & \multicolumn{3}{|l|}{$1.05(0.68,1.61)$} \\
\hline \multicolumn{4}{|l|}{ Wealth index } \\
\hline Lowest & \multicolumn{3}{|l|}{1.0} \\
\hline Second lowest & \multicolumn{3}{|l|}{$0.89(0.58,1.34)$} \\
\hline Middle & \multicolumn{3}{|l|}{$0.59(0.36,0.97)$} \\
\hline Second highest & \multicolumn{3}{|l|}{$0.67(0.34,1.34)$} \\
\hline Highest & \multicolumn{3}{|l|}{$0.43(0.14,1.40)$} \\
\hline \multicolumn{4}{|l|}{ Residence } \\
\hline Urban & \multicolumn{3}{|l|}{1.0} \\
\hline Rural & \multicolumn{3}{|l|}{$0.88(0.61,1.28)$} \\
\hline \multicolumn{4}{|c|}{ Delivery while HIV+ } \\
\hline 1 & \multicolumn{3}{|l|}{1.0} \\
\hline $2+$ & \multicolumn{3}{|l|}{$0.70(0.48,1.00)$} \\
\hline \multicolumn{4}{|l|}{ Partner disclosure } \\
\hline Yes & 1.0 & 1.0 & \\
\hline No & $2.83(1.93,4.13)$ & $1.86(1.22,2.85)$ & 0.04 \\
\hline \multicolumn{4}{|l|}{ Spouse tested } \\
\hline Yes & \multicolumn{3}{|l|}{1.0} \\
\hline No & \multicolumn{3}{|l|}{$2.28(1.58,3.28)$} \\
\hline \multicolumn{4}{|c|}{ Keeping appointments } \\
\hline Not important & 1.0 & 1.0 & \\
\hline Important & $0.46(0.26,0.84)$ & $2.13(0.82,1.95)$ & 0.17 \\
\hline \multicolumn{4}{|c|}{ Keeping baby appointment } \\
\hline Not important & 1.0 & 1.0 & \\
\hline Important & $0.36(0.22,0.60)$ & $0.43(0.20,0.92)$ & 0.03 \\
\hline \multicolumn{4}{|l|}{ Privacy } \\
\hline Yes & 1.0 & 1.0 & \\
\hline No & $2.90(2.03,4.14)$ & $1.86(1.26,2.85)$ & 0.01 \\
\hline \multicolumn{4}{|l|}{ Waiting time } \\
\hline Not long & 1.0 & 1.0 & \\
\hline Long & $1.72(1.18,2.50)$ & $1.32(0.89,1.95)$ & 0.17 \\
\hline
\end{tabular}

Studies have shown that non-disclosure remains a hindrance to prevention efforts against HIV in Africa [31]. In our study, non-disclosure of HIV positive serostatus to the spouse was significantly associated with time to non-retention. Similar findings have been reported in Malawi [32]. The main reason for non-disclosure is the stigma associated with it and yet there is evidence that disclosing one's HIV status lessens the fear of accessing HIV care services [33] especially in our society where cultural norms place dominance on men with regards to women's treatment decisions [34] as well as adherence to infant feeding advice [34].

Socio-economic status, of which education is a component, has been reported as one of the barriers to keeping women in HIV care [22, 35]. We report that women who had no formal education were at increased risk of nonretention. A similar finding has been reported in Kenya [36]. Maternal education has been reported to improve communication between a mother and healthcare provider as it enables mothers to retain information given to them during counselling sessions [37].

The strength of our study is that non-retention was defined as a mother-baby pair missing one scheduled appointment and not turning up at the HIV care point within 30 days of the missed scheduled appointment date. This is opposed to LTFU which considers missing three consecutive scheduled appointments, and yet missing even a single appointment, which affects the continuum of care, may increase the risk of maternal transmission of HIV.

\section{Study limitation}

Data were primarily abstracted from routine care records, and so missed some important variables like education and transport. However, identification and follow-up of the participants were conducted to generate the missing variables. However, there could have been changes in some cases from the time the mothers were first enrolled into care.

\section{Conclusion}

Non-retention of mother-baby pairs in HIV care remains high in Gulu district. Independent factors associated with time to non-retention were; lack of EID services, poor quality of counselling sessions, non-disclosure of mother's HIV status, and understanding the importance of keeping all clinic appointments together with the baby. We, therefore, recommend that health facilities should ensure privacy during counselling sessions which would allow the mothers to remain focussed on the message being passed to them. Health workers should ensure that EID is done at the recommended time to prevent mothers from losing interest and opting out of eMTCT programme. Mothers should be encouraged during counselling sessions, to disclose their HIV serostatus to their spouse.

\section{Abbreviations}

Adj. HR: Adjusted hazards ratio; ART: Antiretroviral treatment; Cl: Confidence intervals; EID: Early infant diagnosis; eMTCT: Elimination of mother-to-child transmission; GRRH: Gulu Regional Referral Hospital; HIV: Human Immunodeficiency Virus; LH: Lacor hospital; UGX: Uganda shilling; WHO: World Health Organisation 


\section{Acknowledgements}

We are grateful to the administrators of GRRH and LH for allowing us to conduct this study in the two hospitals. The research assistants in both hospitals did a wonderful job. The mother-baby pairs who took part in this study cannot be thanked enough for their time and the information they provided. We are grateful to Dr Benjamin Hopwood, Core Medical Trainee, Whiston Hospital, U.K., who edited the manuscript to address typographical and grammatical errors. This work was supported by Training Health Researchers into Vocational Excellence in East Africa (THRiVE); grant number 087540 funded by the Welcome Trust

\section{Funding}

This research was funded by the Welcome Trust grant number 087540 .

\section{Availability of data and materials}

The datasets supporting the conclusions of this article are available upon requests from the first author (email: lekobai@gmail.com).

\section{Authors' contributions}

GO participated in designing the study, data collection, and statistical analyses and served as the lead author of the manuscript. FM and RM played active roles as supervisors during all stages of the study as well as manuscript writing. All the authors read and approved the final manuscript.

\section{Competing interests}

The authors declare that they have no competing interests.

\section{Consent for publication}

Not applicable.

\section{Ethics approval and consent to participate}

Ethical clearance was obtained from Makerere University School of Public Health Higher Degrees Research and Ethics Committee and Lacor Hospital Institutional Review Committee. Written informed consent was obtained from each study participant before the interview. This included participants aged 15-17 years who were included as emancipated minors, as provided for in the Research Ethics Committee guidelines.

\section{Author details}

'Department of Physiology, Faculty of Medicine, Gulu University, P.O. Box 166, Gulu, Uganda. ${ }^{2}$ Department of Disease Control and Environmental Health, Makerere University School of Public Health, P.O Box 7072, Kampala, Uganda. ${ }^{3}$ Department of Epidemiology and Biostatistics, Makerere University School of Public Health, P.O. Box 7072, Kampala, Uganda.

Received: 19 May 2016 Accepted: 11 January 2017

Published online: 18 January 2017

\section{References}

1. UNAIDS. 2013 PROGRESS REPORT ON THE GLOBAL PLAN towards the elimination of new HIV infections among children by 2015 and keeping their mothers alive. November 11, 2013. Available from: http://www.unaids. org/en/media/unaids/contentassets/documents/unaidspublication/2013/ 20130625_progress_global_plan_en.pdf. Accessed 20 Dec 2013.

2. De Cock KM, Fowler MG, Mercier E, de Vincenzi I, Saba J, Hoff E, et al. Prevention of mother-to-child HIV transmission in resource-poor countries: translating research into policy and practice. JAMA. 2000;283:1175-82.

3. Uganda Ministry of Health and ICF-International. 2011 Uganda AIDS indicator survey: Key findings. Calverton, Maryland, USA: MOH and ICF International; 2012.

4. Fabiani M, Nattabi B, Pierotti C, Ciantia F, Opio A.A, Musinguzi J, et al. HIV-1 prevalence and factors associated with infection in the conflict-affected region of North Uganda. BMC Confl Heal. 2007;1(3):1-8.

5. UAC. Global AIDS response progress report. In: Country progress report Uganda. Kampala: Uganda AIDS Commision; 2012.

6. WHO. Prevention of Mother-to-child transmission of HIV-1. 2011. Available from: http://www.who.int/HIV-1/topics/mtct/en/nm. Accessed 14 Jan 2014.

7. UNAIDS. Global Report: UNAIDS Report on the Global AIDS Epidemic 2010 Geneva, Switzeland: UNAIDS; 2010.

8. Moth IA, Ayayo AB, Kaseje DO. Assessment of utilisation of PMTCT services at Nyanza Provincial Hospital, Kenya. SAHARA J. 2005;2(2):244-50.
9. Jones SA, Sherman GG, Varga CA. Exploring socio-economic conditions and poor follow-up rates of HIV-exposed infants in Johannesburg, South Africa. AIDS Care. 2005;17(4):466-70.

10. Ahoua L, Ayikoru H, Gnauck K, Odaru G, Odare E, Ondoa-Onama C, et al. Evaluation of a 5-year programme to prevent mother-to-child transmission of HIV infection in Northern Uganda. J Trop Pediatr. 2010;56:43-52.

11. Kurewa EN, Kandawasvika GQ, Mhlanga F, Munjoma M, Mapingure MP, Chandiwana P, et al. Realities and challenges of a five year follow Up of mother and child pairs on a PMTCT program in Zimbabwe. Open AIDS $\mathrm{J}$. 2011:5:51-8.

12. Kurewa NE, Munjoma MM, Chirenje ZM, Rusakaniko S, Hussain A, Stray-Pedersen B. Compliance and loss to follow up of HIV negative and positive mothers recruited from a PMTCT programme in Zimbabwe. Cent Afr J Med. 2007;53(5-8):25-30.

13 Kim L, Cohan D, Sparks T, Pilliod R, Arinaitwe E, Caughey AB. The Costeffectiveness of repeat HIV testing during pregnancy in a resource-limited setting. J Acquir Immune Defic Syndr. 2013;63(2):195-200.

14 Cook RE, Ciampa PJ, Sidat M, Blevins M, Burlison J, Davidson MA, et al. Predictors of successful early infant diagnosis of HIV in a rural district hospital in Zambézia, Mozambique. J Acquir Immune Defic Syndr (1999). 2011;56(4):e104-9.

15 Kellerman SE and Sugandhi N. Pediatric AIDS in the Elimination Agenda. PLoS Med. 2013;10(8):e1001503.

16 Uganda Bureau of Statistics. National Population and Housing Census 2014. Kampala, Uganda: UBOS; 2014

17 Uganda National Council for Science and Technology (UNCST). National guidelines for research involving humans as research participants. Kampala, Uganda: UNCST; 2014.

18 StatsToDo. Computer Progrm to Calculate Sample Size Requirement for Log Rank Test in Survival Analysis Using Censored Data. [cited 201313 November]; Available from: http://www.statstodo.com/SSizSurvival_Pgm.php\#top.

19 Leslie K. Survey sampling. New York: Wiley; 1965.

20 McCrum-Gardner E. Research methodology series. Sample size and power calculations made simple. Int J Ther Rehabil. 2009:17(1):10.

21 Andersen RM. Revisiting the behavioral model and access to medical care: does it matter? J Health Soc Behav. 1995;36(1):1-10.

22 Kalembo FW, Zgambo M. Loss to Followup: A Major Challenge to Successfu Implementation of Prevention of Mother-to-Child Transmission of HIV-1 Programs in Sub-Saharan Africa. ISRN AIDS Article 2012; 2012(589817).

23 World Health Organisation. WHO recommendations on the diagnosis of HIV infection in infants and children. Geneva: WHO; 2010.

24 Nuwagaba-Biribonwoha H, Mayon-White R, Okong P, Carpenter L. Challenges faced by health workers in implementing the prevention of mother-to-child HIV transmission (PMTCT) programme in Uganda. J Public Health. 2007;29(3):269-74.

25 Painter TM, Diaby KL, Matia DM, Lin LS, Sibailly TS, Kouassi MK, et al. Women's reasons for not participating in follow up visits before starting short course antiretroviral prophylaxis for prevention of mother to child transmission of HIV: qualitative interview study. Br Med J. 2004;329(7465):543-6.

26 Kebede B, Gebeyehu A, Jain S, Sun S, Haubrich R. Delay in early infant diagnosis and high loss to follow-Up among infants born to HIV-infected women in Ethiopia. World J AIDS. 2014;4(4):402-12.

27 WHO, UNICEF, UNAIDS, and PEPFAR. Towards the elimination of mother-tochild transmission of HIV: report of a WHO technical consultation, 9-11 November 2010, Geneva, Switzerland. Geneva: WHO; 2011. p. 82.

28 Patel K, Hernán MA, Williams PL, Seeger JD, McIntosh K, Dyke RB, et al. Long-term effects of highly active antiretroviral therapy on CD4+ cell evolution among children and adolescents infected with HIV: 5 years and counting. Clin Infect Dis. 2008;46(11):1751-60.

29 Raburu JA. Factors influencing quality of maternal health services: a case study of Nyanza and Nakuru provincial hospitals. Kenya Nurs J. 2004;32(2):23-9.

30 Wachira J, Middlestadt SE, Vreeman R, Braitstein P. Factors underlying taking a child to HIV care: implications for reducing loss to follow-up among HIVinfected and -exposed children. SAHARA J. 2012:9:20-9.

31 Atuyambe LM, SSeguja E, Ssali S, Tumwine C, Nekesa N, Nannungi A, et al. HIH/AIDS status disclosure increases support, behavioural change and, HIV prevention in the long term: a case for an Urban Clinic, Kampala, Iganda. BMC Health Serv Res. 2014; 14(276).

32 Njunga I and Blystad A. The divorce program': gendered experiences of HIV positive mothers enrolled in PMTCT programs-the case of Malawi. Int Breast Feeding J. 2010. 5(14). 
33 Przybyla SM, Golin CE, Widman L, Grodensky CA, Earp JA, Suchindran C. Serostatus disclosure to sextual partners among people living with HIV: examining the roles of partner characteristics and stigma. AIDS Care. 2013; 25(5):566-72.

34 Msuya SE, Mbizvo EM, Hussain A, Úriyo J, Sam NE, Stray-Pedersen B. Low male partner participation in antenatal HIV counselling and testing in northern Tanzania: implications for preventive programs. AIDS Care. 2008; 20(6):700-9.

35 Painter TM, Diaby KL, Matia DM, Lin LS, Sibailly TS, Kouassims MK, et al. Sociodemographic factors associated with participation by HIV-1-positive pregnant women in an intervention to prevent mother-to-child transmission of HIV in Côte d'Ivoire. Int J STD AIDS. 2005;16(3):237-42.

36 Moth IA, Ayayo AB, Kaseje DO. Assessment of utilisation of PMTCT services at Nyanza provincial hospital, Kenya. Sahara J. 2005;2:244-50.

37 Mukherjee JS, Ivers L, Leandre F, Farmer P, Behforouz H. Antiretroviral therapy in resource-poor settings: decreasing barriers to access and promoting adherence. J Acquir Immune Defic Syndr (1999). 2006;43(1):123-6.

Submit your next manuscript to BioMed Central and we will help you at every step:

- We accept pre-submission inquiries

- Our selector tool helps you to find the most relevant journal

- We provide round the clock customer support

- Convenient online submission

- Thorough peer review

- Inclusion in PubMed and all major indexing services

- Maximum visibility for your research

Submit your manuscript at www.biomedcentral.com/submit
Biomed Central 